\title{
Polyarteritis Nodosa Complicated by a Multiple Sclerosis Like Syndrome
}

\author{
H. WAISBURG, K. L. MELOFF and R. BUNCIC
}

SUMMARY: $A$ case is presented of a 16-year-old boy with angiographically proven polyarteritis nodosa who developed a multiple sclerosis like syndrome affecting the brain stem and cerebrum. His serum demyelinated nerve in tissue culture. The case is reviewed in detail and the mechanism of myelotoxicity is discussed.

RESUMÉ: Le cas d'un garçon de 16 ans avec polyartérite nodosa prouvée angiographiquement qui développe une sclérose en plaques touchant le tronc cérébral et le cerveau, est présenté. Le sérum de ce patient demyélinisait les nerfs en culture de tissu. Présenté en détail, ce cas sert de raison à une revue du mécanisme de myélotoxicité.

From the Hospital for Sick Children, Toronto, Ontario, Canada.

Reprint requests to: Dr. K. Meloff, Neurology Department, Hospital for Sick Children, Toronto.
This paper is the report of a 16-year-old boy with polyarteritis of four years duration who developed a multiple sclerosis like syndrome. This intermittently affected the brain stem and cerebrum.

Polyarteritis nodosa has protean clinical manifestations reflecting multiple organ involvement and frequently presenting a diagnostic challenge. The lesions occur in medium and small arteries producing a necrotizing inflammatory response and multiple aneurysms (Owano and Sueper, 1963; Frohnert and Sheps, 1967; Rose and Spencer, 1957).

Infantile polyarteritis nodosa is a consistent clinical syndrome with prolonged, often relapsing fever, skin rash, conjunctivitis, evidence of respiratory inflammation, anemia, central nervous system signs, and myocardial involvement with frequent coronary artery disease (Leff et al, 1971; Roberts and Fetterman, 1963; Tang and Segal, 1971; Owano and Sueper, 1963; Fager et al, 1951). In the older child, the picture is often dominated by renal complications, such as chronic glomerulonephritis.

\section{CASE REPORT}

The patient, a boy of Italian descent, was well until July 1967, when, at the age of 11 years, he developed a sore throat, fever, vomiting, tenderness in the left upper abdominal quadrant and hematuria. On admission, he appeared acutely ill, pale and had periorbital edema. His abdomen was flat with marked guarding on the left side. A mass, interpreted as the left kidney, was palpable $5-6 \mathrm{~cm}$. below the left costal margin. Blood pressure was 160/110. The pulse was $104 /$ minute and regular.
The $\mathrm{Hgb}$ was $4.8 \mathrm{gm} / 100 \mathrm{cc}$, WBC $12,700 / \mathrm{cu}$. mm. with a shift to the left, ESR $72 \mathrm{~mm} / \mathrm{hr}$., platelet count $166,000 / \mathrm{cu}$. mm. and reticulocytes $2.3 \%$ of RBC's/cu. mm. Blood cultures were negative. Serum iron was $67 \mu \mathrm{g} / 100 \mathrm{ml}$. Serologic tests for syphylis were negative. BUN and electrolytes were normal. The ASO titre was 300 Todd units. Protein electrophoresis revealed $\boldsymbol{\gamma}$-globulin of $2.05 \mathrm{gm} / 100 \mathrm{ml}$. A Coomb's test was'negative. Several LE tests were negative. Prothrombin time was 14 sec. and the partial thromboplastin time was $32 \mathrm{sec}$. Fetal hemoglobin was $1.3 \%$ and hemoglobin electrophoresis was normal.

Urinalysis done on several occasions revealed $10-15 \mathrm{wbc}, 10-20 \mathrm{rbc}$, hyaline and wbc casts and 2 talbumin. Urine culture was negative. A bone marrow and a skin and muscle biopsy were normal. An intravenous pyelogram showed the right renal system to be normal; the left collecting system, however, was poorly filled and appeared to be displaced forward by an intracapsular mass.

A renal angiogram revealed multiple aneurysms involving the peripheral branches of both renal arteries, mainly on the left side. At the lower pole of the left kidney, there was a non-opacified area thought to represent an intracapsular hematoma. The diagnosis of polyarteritis nodosa was made at this time.

The boy was transfused with whole blood for his anemia. His elevated blood pressure responded to a regimen of reserpine and hydralazine. His abdomen softened and the mass in his left upper quadrant became smaller and less tender. The urine improved and at the time of discharge, the protein was almost 
absent and cells and casts were absent.

About two weeks after admission, the patient developed brisk deeptendon reflexes in his lower extremities, bilateral upgoing toes and ankle clonus. These resolved spontaneously within a week. One month later, at the time of discharge, $\mathrm{Hgb}$ was $10.8 \mathrm{gm} . \%$, ESR has fallen to 34 $\mathrm{mm} / \mathrm{hr}$. and platelet count was normal.

Over the next year he was examined monthly in the renal clinic. BUN, Hgb and electrolytes remained normal. The blood pressure fluctuated between $120 / 70$ and $130 / 90$ and $1+$ to $2+$ proteinuria persisted.

He was readmitted in June 1968 , at age 12 years to evaluate the persistent left flank mass. The IVP was normal except that the left renal outline was slightly enlarged compared with the right. The renal angiogram was repeated. The aneurysms of the peripheral branches of the renal arteries were less prominent than previously. The lower pole of the left kidney did appear to be slightly small, perhaps secondary to scarring. He was discharged in July 1968.

In August, 1970, at age 14, he began to complain of periodic stiffness and tingling of his fingers. Eighteen months later, he was readmitted with a 48 hour history of sudden hearing loss on the left side, vertigo, nausea, vomiting and non-lateralized ataxia.

On examination he had a strong, right beating, spontaneous, horizontal nystagmus with rotatory element; left lower motor neuron facial weakness; complete hearing loss on the left side; and minimal pyramidal signs on the left side. An electroencephalogram was normal. The cerebrospinal fluid protein was 25 mg. \%. Ice water caloric stimulation of the left ear produced no response. Audiometric studies revealed total left nerve deafness and a loss of the 4000 frequency tone in the right ear. The creatinine clearance was 65 $\mathrm{mg} / \mathrm{ml} / \mathrm{m}^{2}$.

Within two weeks all the neurological signs and symptoms had cleared up except for the total deafness of the left ear. He was discharged and about six months later, in September, 1972, he had a sudden numbness and weakness of the left side of the body which cleared up in 48 hours.

In November of 1972, he was again admitted because of the sud den onset of severe left flank pain. On examination he was pale, the blood pressure was $140 / 100$, and the pulse $96 /$ minute. There was no cardiomegaly. In the 24 hours following admission the neurological status deteriorated. His mental status was intact but he developed the following signs: limited right eye abduction to about $50-60 \%$, a dissociated nystagmus of the abducting left eye with slowed saccadic movements of the right medial rectus; bilateral jerky nystagmus on upward gaze. Cold caloric stimulation of the right ear, partially improved abduction of the right eye and produced a beating nystagmus in the left eye. These findings represented a right internuclear ophthalmoplegia with a partial right sixth nerve palsy and an intact right vestibular apparatus. Caloric stimulation of the left ear produced no response.

The pupils were normal in appearance and reactive to light. Corneal reflexes were present bilaterally. There was a complete right lower motor neuron facial palsy and total left sensorineural deafness. The rest of the cranial nerves were intact. Mild pyramidal signs were present on the left side of the body. The toes were upgoing bilaterally. Sensation for pain and touch was decreased on the right side of the body with a sensory level at $C_{4}-C_{5}$. Other sensory modalities were intact. Marked gait and truncal ataxia was present associated with severe dizziness, and a tendency to fall to the left with eyes opened or closed.

He was treated with prednisone 60 mg. a day with marked improvement of his neurological status. At the time of discharge, four weeks later, he was left with a mild right facial palsy, a partial right sixth nerve palsy, a right internuclear ophthalmoplegia, mild truncal ataxia, a sen- sory level on the right at $\mathrm{L}_{1}$ to $\mathrm{L}_{2}$, bilateral upgoing toes and his old sensorineural hearing loss on the left side.

The nerve conduction velocity was slow in the lower limbs ( 30 $\mathrm{m} / \mathrm{sec}$.) and the brain scan was normal. The EEG showed diffuse disturbances of function in the postcentral regions. The CSF protein was normal (27 $\mathrm{mg} . \%)$ and the CSF protein electrophoresis revealed a normal pattern, with normal levels of gamma globulin. A vertebral angiogram did not indicate any vascular abnormality. The antinuclear factor was positive.

Myelinated cultures of rat cerebellum underwent a specific and characteristic pattern of demyelination in the presence of the patient's serum. The neuroglia swelled, and the myelin sheaths became disfigured by fusiform swellings and broke away to small fat droplets.

In May, 1973, at the age of 16 years, he was again admitted after a sudden episode of loss of consciousness, followed by confusion, dysarthria, and a right flaccid hemiparesis. This clinical picture improved in 48 hours without treatment and seven days after the onset a brain scan was abnormal, showing an increased uptake in the territory of the left middle cerebral artery, suggesting a cerebral infarction.

\section{DISCUSSION}

The difficulty of establishing the diagnosis of polyarteritis nodosa has been stressed by many authors (Rose and Spencer, 1957; Griffith and Vural, 1951). Skeletal muscle biopsy confirms the specific vascular lesion in only 20 to $35 \%$ of cases (Maxeiner et al, 1952).

The kidney is involved in 80 to $100 \%$ of cases of polyarteritis in late childhood and adulthood. Aneurysm formation with rupture is sometimes the cause of death in these patients and usually occurs early. Several cases of polyarteritis nodosa have been reported in which perirenal and retroperitoneal hemorrhages were due to the rupture of a renal aneurysm (Wever and Perry, 1935; Fort, 1948; McGrae, 1959; Horn and 
Heller, 1949; Ralston and Kvale, 1949). In our patient, who presented clinically like an acute glomerulonephritis, it is reasonable to infer that the intracapsular hematoma was due to rupture of an aneurysm in the kidney. The important role of arteriography to demonstrate these lesions and confirm the diagnosis of polyarteritis nodosa has been stressed by others (Bron et al, 1965; Fleming and Stern, 1965). The neurological complications of polyarteritis nodosa are extremely variable (Foro and Siekert, 1965; Lovelace, 1964; Glaser, 1955). Involvement of the peripheral nerves is common. About half of the cases have polyneuropathy or mononeuritis multiplex. Focal or disseminated central nervous system involvement can occur at any time during the course of the disease, with headaches, convulsions, vertigo, sudden loss of vision in one eye, confused states, organic psychosis, stroke, focal weakness, and an isolated or combined cranial neuropathy. There are two special types of polyarteritis nodosa with neurological manifestations. One is temporal arteritis and the other is characterized by the association of keratitis, bilateral vestibular symptoms and deafness in young adults with no evidence of syphilis (Crawford, 1957).

Our patient had involvement of peripheral nerves, brain stem vestibular apparatus and cerebrum, and the symptoms and signs exacerbated and remitted affecting different parts of the nervous system at different times, mimicking multiple sclerosis.

The myelotoxic effect of the patient's serum on rat brain has been described in more than $60 \%$ of cases of multiple sclerosis (Bornstein and Appel, 1961; Bornstein, 1963). This myelinolytic effect apparently resides in the gamma 2 globulin (Appel and Bornstein, 1964). Antibrain antibodies have been seen in a variety of other conditions including Huntington's Chorea, presenile dementia, Hashimoto's thyroiditis, rheumatoid arthritis, systemic lupus erythematosus, viral encephalitis, Guillain-Barré syndrome, and experimental allergic encephalomyelitis (Kies et al, 1965). The destructive effect could be a "marker" of autoimmune disease or a nonspecific effect due to production of antibodies in response to any form of brain damage.

To our knowledge, this is the first case of angiographically proven polyarteritis nodosa associated with a myelotoxic effect of serum on nerve in tissue culture.

The authors are indebted to Dr. Murray B. Bornstein, Professor of Neurology, Albert Einstein College of Medicine, for performing these studies and for reviewing the manuscript.

Dr. Bornstein's work is supported by National Multiple Sclerosis Society Grant No. 788 and N.I.N.D.S. Grant NS06735.

\section{REFERENCES}

APPEL, S. H. and BORNSTEIN, M. B. (1964). The Application of Tissue Culture to the Study of Experimental Allergic Encephalomyelitis. Journal of Experimental Medicine 119, 303-312.

BORNSTEIN, M. B. (1963). A Tissue Culture Approach to Demyelinative Disorders. National Cancer Institute Monograph No. 11, 197-214.

BORNSTEIN, M. B. and APPEL, S. H. (1961). The Application of Tissue Culture to the Study of "Experimental" Allergic Encephalomyelitis I. Patterns of Demyelination. Journal of Neuropathology and Experimental Neurology 20, 141-157.

BRON, K., STROTT, C. A. and SHAPIRO, A. P. (1965). The Diagnositic Value of Angiographic Observations In Polyarteritis Nodosa. A Case of Multiple Aneurysms in the Visceral Organs. Archives of Internal Medicine 116, 450-454.

CRAWFORD, W. (1957). Cogan's Syndrome Associated with Polyarteritis Nodosa - A Report of Three Cases. Pennsylvania Medical Journal 60, 835-838.

FATER, D. B., BIGLER, J, A. and SIMONDS, J. P. (1951). Polyarteritis Nodosa in Infancy and Childhood. Joumal of Pediatrics 39, 65-79.

FLEMING, R. J. and STERN, L. A. (1965). Multiple Intraparenchymal Renal Aneurysms in Polyarteritis Nodosa. Radiology 84, 100-103.

FORD, R. and SIEKERT, R. (1965). Central Nervous System Manifestations of Periarteritis Nodosa. Neurology 15, 114-122.
FORT, C. A. (1948). Spontaneous Perirenal Hematoma Secondary to Periarteritis Nodosa. Journal of Urology 59, 307-311.

FROHNERT, P. and SHEPS, S. G. (1967). Long Term Follow-up Study of Periarteritis Nodosa. American Journal of Medicine 43, 8-14.

GLASER, G. H. (1955). Neurologic Manifestations In Collagen Diseases. Neurology 5 , 751-766.

GRIFFITH, G. C. and VURAL, I. L. (1951). Polyarteritis Nodosa: A Correlation of Clinical and Postmortem Findings in 17 Cases. Circulation 3, 481-491.

HORN, R. H. and HELLER, E. L. (1949). Massive Perirenal Hemorrhage in Periarteritis Nodosa. Annals of Internal Medicine 30, 1060-1064.

KIES, M. W., ALVORD, E. C. and SHAW, C. M. (1965). Anti-brain Antibodies in Slow Latent and Temperate Virus Infections (D. C. Gajdusek, Clarence J. Gibbs, Jr., and Michael Alpers, Eds.). N.I.N.D.B. Monograph No. 2 159-167. Public Health Service Publication No. 1378. U.S. Dept. of Health, Education and Welfare, Washington, D.C.

LEFF, R., HARPER, W. V., BAYLIS, J. C., JACKSON, L. and FABER, K. (1971). Polyarteritis Nodosa in Two Siblings. American Journal of Diseases in Children 121, 67-70.

LOVELACE, R. E. (1964). Mononeuritis Multiplex in Polyarteritis Nodosa. Neurology 14, 434-442.

MAXEINER, S. R., McDONALD, J. R. and KIRKLIN, J. W. (1952). Muscle Biopsy in the Diagnosis of Periarteritis Nodosa. Surgical Clinics of North America 32, 1225-1233.

McGRAE, J. D. JR. (1959). Perirenal Hematoma Secondary to Polyarteritis Nodosa: Report of a Case and Review of the Literature. Archives of Internal Medicine 104, 421-426.

OWANO, L. and SUEPER, R. H. (1963). Polyarteritis Nodosa: A Syndrome. American Journal of Clinical Pathology 40, 527-531.

RALSTON, D. E. and KVALE, W. F. (1949). The Renal Lesions of Periarteritis Nodosa. Proceedings of the Mayo Clinic 24, 18-27.

ROBERTS, F. B. and FETTERMAN, G. H. (1963). Polyarteritis Nodosa In Infancy. Journal of Pediatrics 63, 519-529.

ROSE, G. A. and SPENCER, H. (1957). Polyarteritis Nodosa. Quarterly Journal of Medicine 26, 43-81.

TANG, P. H. and SEGAL, A. (1971). Polyarteritis Nodosa of Infancy. Fatal Late Complication. Journal of the American Medical Association 217, 1666-1670.

WEVER, G. K. and PERRY, I. H. (1935). Periarteritis Nodosa: Report of a Case with Fatal Perirenal Hemorrhage. Journal of the American Medical Association 104, 1390-1395. 